\title{
Estimation of Temperature Rise During Ion Milling of Samples
}

\author{
Young-Woon Kim and Kyung-Woo Yi \\ School of Materials Science and Engineering, Seoul national University \\ Kwanak-ku Shinlim9-dong Seoul Republic of Korea
}

The sample preparation step for transmission electron microscopy is known to be one of the bottlenecks for the critical analysis. Most of the electron microscopists are aware of the temperature rise during the ion milling, but the quantitative measurement has not been accomplished together with the theoretical calculations.

Actual temperature rise during ion milling was measured using the special probes with thermocouples embedded. Two types of probes were used in the measurement. A shielded probe, stainless steel sheathed K-type thermocouple in $\mathrm{MgO}$ insulation, was mainly used to measure the temperature under ion beam, while the other type, bare Ktype thermocouple coated with Mbond 610[1], was used to measure the temperature for a short period of time. Both probes, shown in Figure 1, have a similar shape to the actual 3$\mathrm{mm}$ disc of TEM samples. These two different probes were used to measure the actual temperature with ion beam shining in the most commonly used two ion milling systems. The temperature reached as high as $296{ }^{\circ} \mathrm{C}$ with the bare probe when a single ion gun was used to mill the sample at $5 \mathrm{keV}$ with 80 degrees of incidence angle. On the other hand, the sheathed probe revealed the temperature rise up to $198^{\circ} \mathrm{C}$ as shown in Figure 2 . Theoretical calculation was made to match the measurement with the calculated value. Calculations were made with the setup of the geometry and thickness of the sample followed by iterative calculation with heat addition by ion beam and extraction by conduction. It is mentioned that the energy deposited onto the sample could be as high as $150 \mathrm{~mW}$ per gun[2]. With this number of energy deposition, the temperature of the sample could rise more than $300^{\circ} \mathrm{C}$ according to the calculation.

Other forms of artifacts are also investigated. In $\mathrm{Si}(001)$, the ion-induced damage layer on the surface reached as thick as $3.46 \mathrm{~nm}$ when $5 \mathrm{keV}$ argon ions were bombarded at 75 degrees of incidence from the surface normal. This number is compared with the numbers obtained from other measurement techniques of damaged layer. In foils of gold, ion induced damage appeared as a small cluster of defects, could not be removed even after annealing at $200{ }^{\circ} \mathrm{C}$, which was not visible in the sample prepared using focused ion beam.

[1] Measurement group INC., Raleigh, North Carolina 27611 USA

[2] Gatan Manual, Precision Ion Polishing System , July 1997, rev. 1

[3] The authors wish to thank to Center for Microanalysis of Materials at University of Illinois at Urbana-Champaign. 

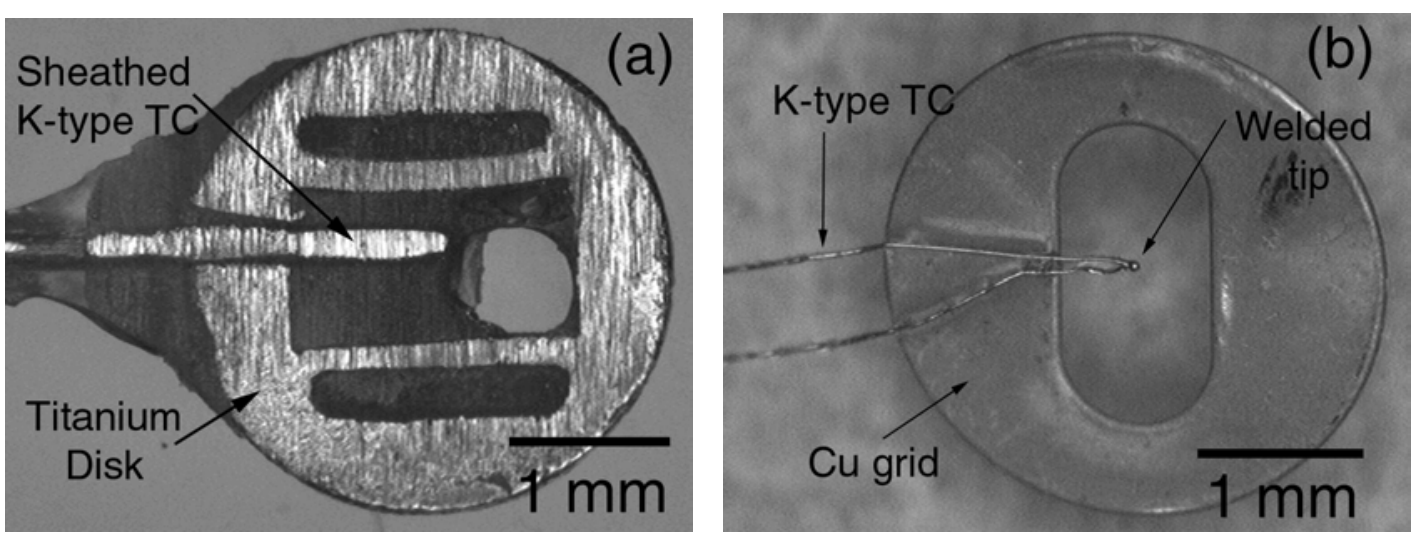

Figure 1. Two samples used to measure the temperatures with ion beam milling. (a) A sheathed, ungrounded, K-type thermocouple was mounted on a titanium disc. Center thickness was about $200 \mu \mathrm{m}$. (b) Bare K-type thermocouple was coated with Mbond 610, then mounted on a copper grid. Welded bead edge of the foil. diameter is about $40 \mu \mathrm{m}$.

\section{Temperature variation with ion beam}

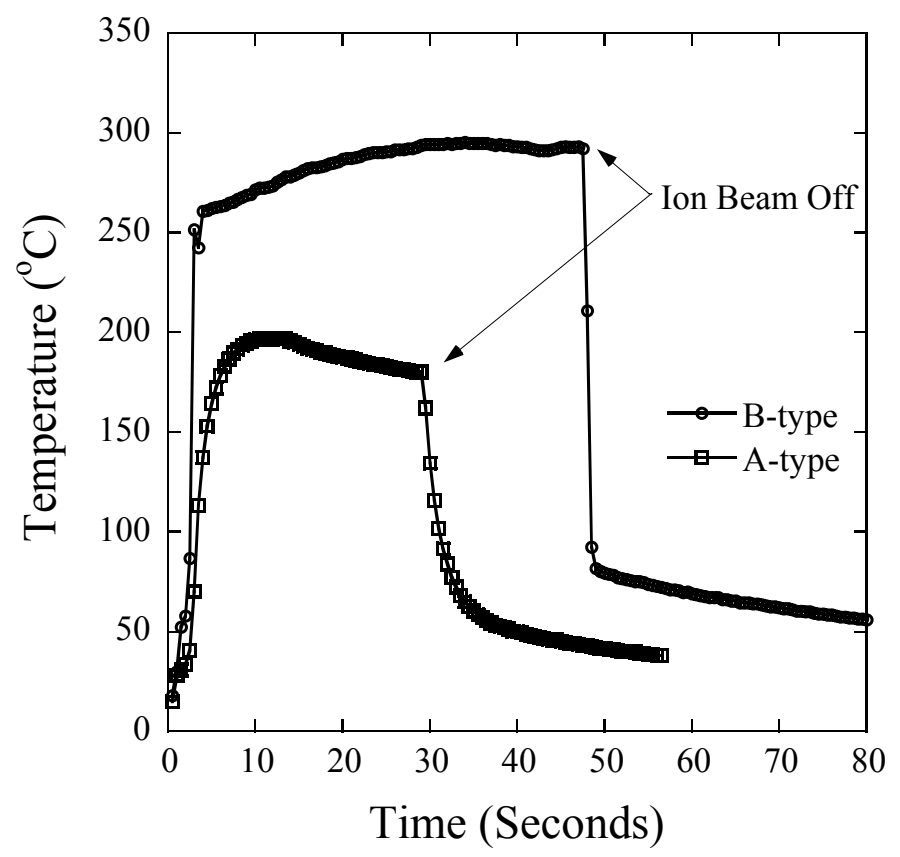

Figure 2. Temperature variation of $\mathrm{A}$ and $\mathrm{B}$ type samples when $6 \mathrm{keV}$ ions were bombarded at 80 degrees of incidence. Ion beam was turned on at time 0 second and turned off at the point marked with arrows. 